\title{
MODELLING ROOM COOLING CAPACITY WITH FUZZY LOGIC PROCEDURE
}

\author{
H. O. Adeyemi ${ }^{1}{ }^{*}$, Z. 0. 0. Jagun ${ }^{2}$, S. 0. Giwa ${ }^{3}$, O. R. Adetunji ${ }^{4}$ and R. A. Owamoyo ${ }^{5}$

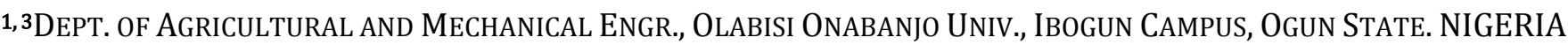 \\ 2DEPT. OF ELECTRICAL AND COMPUTER ENGR., OLABISI ONABANJO UNIVERSITY, IBOGUN CAMPUS, OGUN STATE. NIGERIA

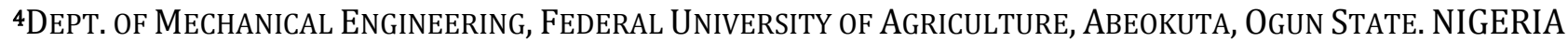

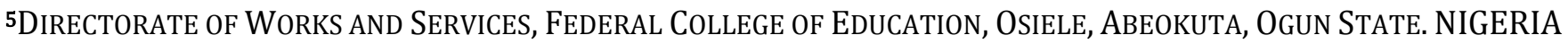 \\ E-mail addresses: ${ }^{1}$ adeyemi.hezekiah@oouagoiwoye.edu.ng, ${ }^{2}$ jagun.zaid@oouagoiwoye.edu.ng, \\ 3sologiwa2002@yahoo.com,4adetunjiolayide@gmail.com,5raphew4k@yahoo.com
}

\begin{abstract}
The primary aim of this study is to develop a model for estimation of the cooling requirement of residential rooms. Fuzzy logic was employed to model four input variables (window area $\left(\mathrm{m}^{2}\right)$, roof area $\left(\mathrm{m}^{2}\right)$, external wall area $\left(\mathrm{m}^{2}\right)$ and internal load (Watt). The algorithm of the inference engine applied sets of 81 linguistic rules to generate the output variable in Cooling Load rating. A paired t-test was carried out using SPSS version 20 package, with the results of human professionals' calculations for each assessed rooms compared with the model generated Cooling Load capacities for the same set of variables. The human calculation and model results were observed to be strongly correlated $(r=0.880, p<0.001)$ with no significant difference between the two sets of variables $\left(t_{19}=-\right.$ $1.697, p>0.001)$. On the average, human calculation values were 221.5 points lower than model calculated values (at 95\% confidence interval [-447.55, 4.50]). The study proposed a model to size the cooling capacity of residential rooms. The model is capable of providing results comparable to that of human professionals in the application area. It is simple and can find its usefulness among building consultants/professionals and home owners.
\end{abstract}

Keywords. Fuzzy logic, cooling capacity, residential rooms, input variable

\section{INTRODUCTION}

Modelling is an indispensable problem-solving methodology which can be used to; describe and analyse the behaviour of a system, ask what-if questions and; provide information to aid in the design and development of the real system. According to Idener [1], one purpose of a model is to enable the effect of changes to a given system to be predicted. On the one hand, a model is a close approximation to the real system and incorporates most of its salient features.

The logic model process is a tool that has been used over years by program managers and evaluators to describe the effectiveness of their programs. Once a program has been described in terms of the logic model, critical measures of performance can be identified [2]. Logic models are narrative or graphical depictions of processes in real life that communicate the underlying assumptions upon which an activity is expected to lead to a specific result [3].
Modelling with fuzzy logic is an approach to forming the system mode using a descriptive language based on fuzzy logic with fuzzy propositions. This linguistic approach of system modelling can be formulated by three distinct features: the use of linguistic variables in place of or in addition to numerical variables; the characterization of simple relations between variables by IF-THEN fuzzy rules; and the formulation of complex relations by fuzzy reasoning algorithms [4] Several efforts were made to develop various models in the area of Heating, Ventilating, and Air Conditioning (HVAC) system. To mention few, Mullen and Bullard [5] developed a room air conditioner simulation model using heat transfer and pressure drop correlations. The governing equations were solved using the Newton-Raphson method. Cutler et al., [6] presented improved air conditioner and heat pump modelling methods in the context of wholebuilding simulation tools. Its goal was to enable more accurate evaluation of cost-effective equipment 
upgrade opportunities and efficiency improvements in residential buildings. Lu, et al [7] developed air conditioner compressor performance model which is a fair representation of the motor behaviours in both running and stalling states. Mohammad and Majid [8] developed a comprehensive load estimation modelling of vehicle air conditioning using heat balance method which used the cabin geometry and material properties as the inputs.

It was however noted that: application of fuzzy logic in this area is not fully exploited and; there is shortage of experienced human practitioners. There is the need for automatic and economical supplementary tools that will allow expertise input into design process [9]. Reasoning based on fuzzy models was however identified to provide an optional direction of handling the way humans think and make judgments [10]. This study developed and validated a model capable of estimating the cooling capacity of residential room and recommend the rate required in Cooling Load (BTUs).

\section{MATERIALS AND METHODS}

\subsection{Fuzzy Logic}

Fuzzy Logic Theory (FLT) provides the most suitable tool for transforming linguistic terms associated with the input variables of a problem to fuzzy numbers. The linguistic variables is the essential for fuzzy theory. It builds a bridge from the nature language words to fuzzy logic. It belongs among methods that are used in the area of decision makings [11]. It has high abilities in the prediction and modelling of human knowledge because its approach to problems mimics how a person would make decisions, only much faster [12, 13]. Fuzzy logic can deal with the vagueness intrinsic to human thinking and natural language. It deals with uncertainty and can model common sense reasoning which is very difficult for general systems [10]. A fuzzy system is a static nonlinear mapping between its inputs and outputs. A fuzzy set has values with partial membership along with the crisp values. Elements in a fuzzy set can overlap, so a given crisp value can belong to multiple fuzzy sets with different membership degrees in each set [14]. One of the basic principles of fuzzy logic is the degree of membership determined by "fuzzifying" each data point using the input fuzzy set. The input fuzzy set is determined by the system designer to break down the complete range of possible input values into membership functions (MFs). Each MF has a value of either 0 or 1 and a range specifying the minimum and maximum input values [15]. Fuzzy logic has been widely applied in the areas of engineering, design, diagnostics, control [16], artificial intelligence and expert systems $[17,18]$ to mention few.

\subsection{Membership Functions}

There are different forms of Membership Functions (MFs) in fuzzy logic applications these include triangular, trapezoidal, piecewise linear, Gaussian, or singleton. The trapezoidal MF used in this study (Figure 1), has a flat top. It is defined by a lower limit $a$, an upper limit $d$, a lower support limit $b$, and an upper support limit $\mathrm{c}$, where $\mathrm{a}<\mathrm{b}<\mathrm{c}<\mathrm{d}$. This straight line MFs have the advantage of simplicity and have more applicability in modelling.

\subsection{Data Collection}

\subsubsection{Model Development}

In this study, we have proposed a model which estimates room cooling ratings of residential building in Abeokuta, Southwest Nigeria. As shown in Figure 2, there are four input variables considered among others relevant to sizing cooling requirement of a residential room as stated in equations (1-9) by [19]. According to Mustafa and Kevin [20], for a standard fuzzy systems where the input membership functions are defined on a grid on the input space, and all possible combinations of rules are used, there is an exponential growth in the number of parameters of the fuzzy system as the number of input dimensions increases. This leads to problems with design of fuzzy controllers, training of fuzzy estimators, and with computational complexity. Hence, to solve the rule explosion problem, input variables that produce only those rules that contribute the most to the inference outcome of the model were selected and used in this study. These include; window area $\left(\mathrm{m}^{2}\right)$, roof area $\left(\mathrm{m}^{2}\right)$, external wall area $\left(\mathrm{m}^{2}\right)$, and internal load (Watt).

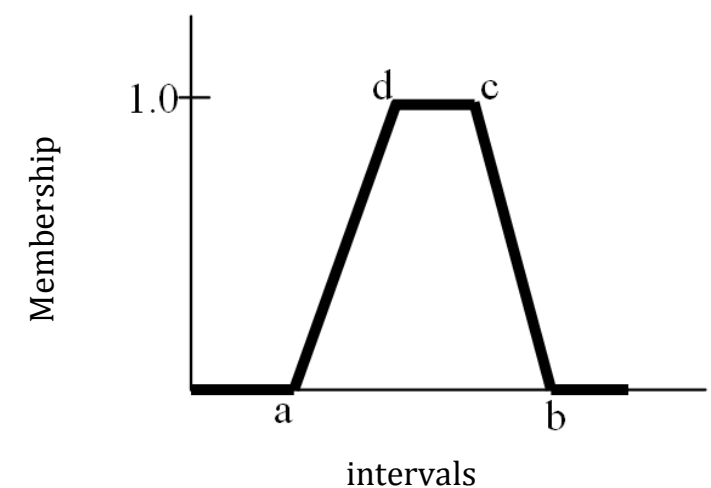

Figure 1: Typical continuous fuzzy set membership function trapezoidal shape

Vol. 35, No. 3, July 2016 
Trained personnel were involved in data collection for all the required parameters as detailed by the ASHRAE load components. A total of 115 air conditioned rooms of residential buildings were assessed for recording of variables. Occupancy comfort levels using the assessed air conditioner capacity were measured with a set of questionnaire. Responses of users to whether the sizes of air conditioners in use are comfortable or not were recorded. Measurements of all areas $\left(\mathrm{m}^{2}\right)$ are products of length $(\mathrm{m})$ and breadth $(\mathrm{m})$, which were measured using meter rule. Power ratings of all appliances and lighting were recorded from the manufacturers' manual. Human professionals were involved in the manual calculations of the variables using equations (1) to (9) on Excel spreadsheets [21] following the procedures outlined in the ASHRAE load components guideline.

Load (q)from Window Area $=(G L F) A$

Load (q)from Ceiling and Roof Area $=\mathrm{U}_{\mathrm{r}} \mathrm{A}($ CLTD)

Load (q) from Doors $=U_{d} A(C L T D)$

Load (q) from Exterior walls $=\mathrm{U}_{\mathrm{w}} \mathrm{A}$ (CLTD)

Load (q) from partitions to unconditioned space

$$
=\mathrm{U}_{\mathrm{p}} \mathrm{A} \Delta \mathrm{t}
$$

Load (q) from internal heat sources (people, appliances, light $=67 \mathrm{~W}$ per person)

Load $(q)$ from infiltration $=1.2 \mathrm{Q} \Delta \mathrm{t}$

$Q=\operatorname{ACHx}($ roomvolume $) \times \frac{1000}{3600}$

The total cooling load (sensible plus latent) may be estimated by applying the Latent Factor (LF).

The total cooling load $=\mathrm{LF} \times$ total sensible load

$$
=1.15 \times \mathrm{xq}_{\mathrm{rm}} \text {. }
$$

Where $\mathrm{q}_{\mathrm{rm}}=$ room sensible cooling load, $\mathrm{W}$

The total design flow from the air conditioner can be estimated using equation (9)

$$
Q_{w t}=\frac{1000 q_{r m}}{1.2 \Delta \mathrm{t}}
$$

where

$Q_{w t}$ is the total airflow, $\mathrm{L} / \mathrm{s}$

Density of air times specific heat of cooling air is 2.1. (At sea level and at $15^{\circ} \mathrm{C}$, air has a density of approximately $1.225 \mathrm{~kg} / \mathrm{m}^{3}$ and the specific heat of cooling air $=1.01[\mathrm{~kJ} / \mathrm{kg} . \mathrm{K}]$ ).

$\Delta t$ is the temperature difference of air entering and leaving room, $\mathrm{K}$

Using 1Litres-atmosphere per second equivalent to 345.74 Btu per hour, the Cooling Load of each room was manually computed by human professionals.

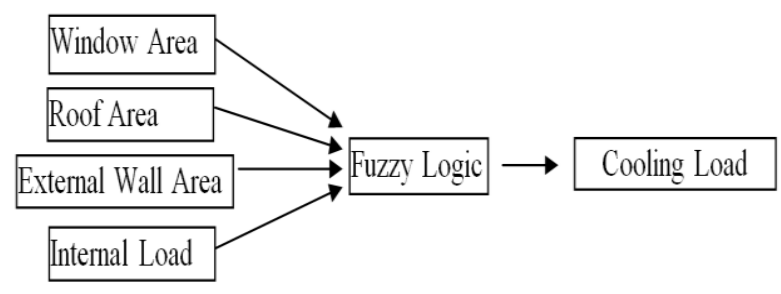

Figure 2: Fuzzy logic model for room cooling load estimation

\subsection{Fuzzification of Input Variables}

There are three general types of fuzzifiers used to associate a grade to linguistic term, singleton fuzzifier, gaussian fuzzifier and trapezoidal or triangular fuzzifier [22]. Since the data used in this study are vague, it was required that they be converted into fuzzy numbers. The crisp variables are transformed into grades of membership for linguistic terms of fuzzy sets. Intervals of all linguistic variables were carefully set and number of MFs determined as well as the baselines.

\subsection{Fuzzy Rule Base and Inference Generation:}

A fuzzy rule is a simple IF-THEN rule with a condition and a conclusion [23]. When both the antecedents and the consequences of rules are expressed in fuzzy value form, we have a set of general fuzzy 'If-Then Rules'. The relationship between heuristic, input and output parameters enabled the formation of 'If Then Rules'. With the help of the defuzzification method, it is possible to construct the proposed matrix formulation [24]. This study used four inputs each having three (3) variables. This gave a rule base matrix with size $3^{4}$ resulting in total sets of 81 matrices.

The model was implemented in MATLAB ${ }^{\circledR}$. MATLAB provides symbolic solution and a visual plot of result [25] and creation of user interfaces [26]. For each sample, all the four variables are fuzzified by the application. Active MF are calculated according to rule table, using the Mamdami techniques. The output, Cooling Load, is defuzzified by calculating the center (centriod) of the resulting geometrical shape. This sequence is repeated for each sample.

\subsection{Model Validation and Statistic Analysis:}

Using a paired t-test on SPSS version 20 package, the results of human calculations for each assessed rooms are compared with the model generated Cooling Load capacities for the same set of variables. A paired t-test can be used to compare two different sets of variables and test the null hypothesis that the difference between two related means is 0 [27]. 


\section{RESULTS AND DISCUSSION:}

\subsection{All Fuzzy Sets and the Membership Functions for} the Input Variables:

Tables 1-4 show all the fuzzy sets for input variables while Figure 3 to 6 are all the MFs for the input variables. Table 5 and Figure 7 are the output fuzzy sets and the output MF variables of the model respectively.

The system linguistic terms and intervals were developed from an expert knowledge, who detailed three linguistic terms to all the four variables and assigned intervals based on data collected. All intervals for each of these linguistic values are stated.

Table 1: Fuzzy set of input variable 'Window Size'

\begin{tabular}{ll}
\hline LINGUISTIC TERMS & INTERVAL \\
\hline Small Window (SW) & $1.08,1.2,1.44,1.6$ \\
Large Window (LW) & $1.44,1.6,1.92,2.1$ \\
Extra Large Window (ELW) & $1.9,2.1,2.8,3.0$ \\
\hline
\end{tabular}

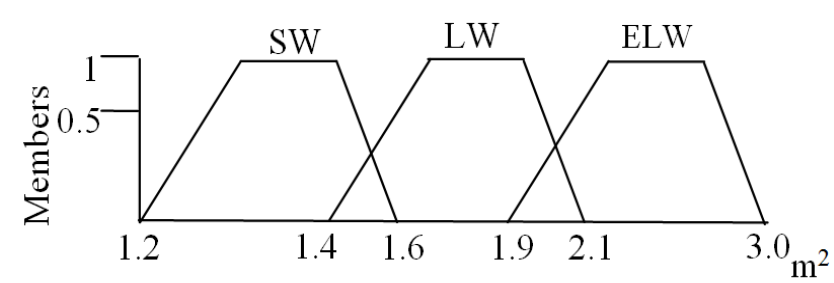

Figure 3:-Membership Function Showing the Fuzzy Sets of 'Window Size'

Table 2: Fuzzy set of input variable 'Roof Area'

\begin{tabular}{ll}
\hline LINGUISTIC TERMS & INTERVAL \\
\hline Small Roof (SR) & $3,6,8,10$ \\
Medium Roof (MR) & $8,10,14,15$ \\
Large Roof (LR) & $13,16,20,23$ \\
\hline
\end{tabular}

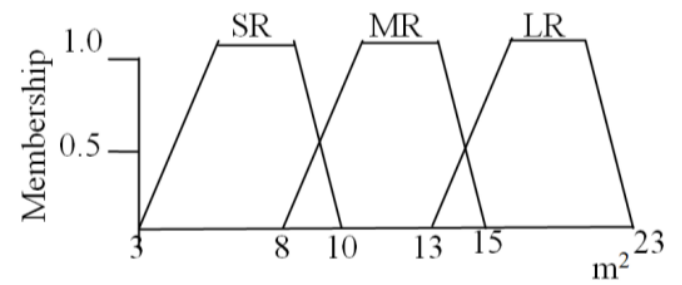

Figure 4:-Membership Function Showing the Fuzzy Sets of 'Room Floor Area'

Table 3: Fuzzy set of input variable 'Internal Load'

\begin{tabular}{ll}
\hline LINGUISTIC TERMS & INTERVAL \\
\hline High Load (HL) & $250,300,350,470$ \\
Medium Load (ML) & $200,210,250,300$ \\
Light Load (LL) & $0,0,200,210$ \\
\hline
\end{tabular}

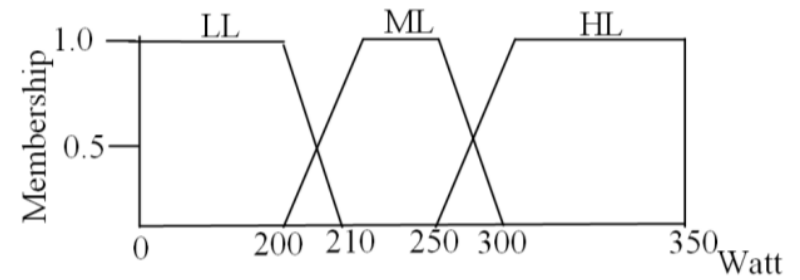

Figure 5:-Membership Function Showing the Fuzzy Sets of 'Internal Load'

Table 4: Fuzzy set of input variable 'Exterior Wall'

\begin{tabular}{ll}
\hline LINGUISTIC TERMS & INTERVAL \\
\hline Small Size (SZ) & $5,7,8,9$ \\
Medium Size (MZ) & $8,9,13,17$ \\
Large Size (LZ) & $13,17,21,24$ \\
\hline
\end{tabular}

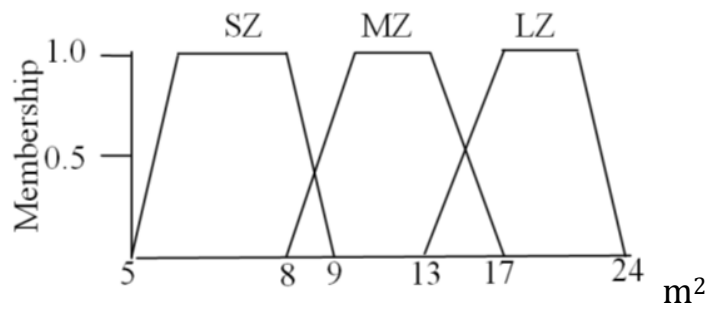

Figure 6:- Membership Function Showing the Fuzzy Sets of "Exterior Wall"

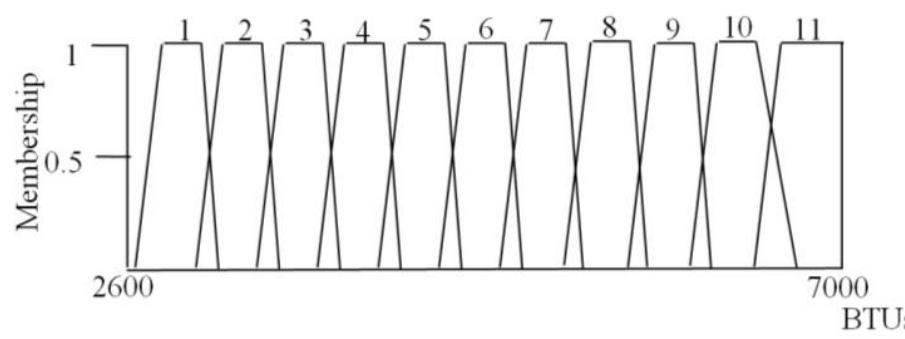

Figure 7:- Membership Function Showing the Fuzzy Sets of Output Variable 'Cooling Capacity'

Table 5: Fuzzy set of output variable 'Cooling Capacity'

\begin{tabular}{cc}
\hline VALUES & INTERVAL \\
\hline 1 & $2600,2800,3000,3200$ \\
2 & $3000,3200,3400,3600$ \\
3 & $3400,3600,3800,4000$ \\
4 & $3800,4000,4200,4400$ \\
5 & $4200,4400,4600,4800$ \\
6 & $4600,4800,5000,5200$ \\
7 & $5000,5200,5400,5600$ \\
8 & $5400,5600,5800,6000$ \\
9 & $6200,64000,6200,6400$ \\
10 & $6600,6800,7000,6800$ \\
11 &
\end{tabular}

\subsection{Fuzzy Rules Generation For The Model:}

Table 6 shows the matrix representation of the fuzzy rules for the model. Each cell has eight resulting command which is made possible when the input variables take the values in the first two columns and 
two upper rows. Each cell contains 9 output value of corresponding combination of antecedents variables. All necessary conditions as stated in Equation (1) - (7) are carefully considered to produce the resulting intervals in Table 5.

Table 6 : Fuzzy Base Rules Table For Cooling Load Values

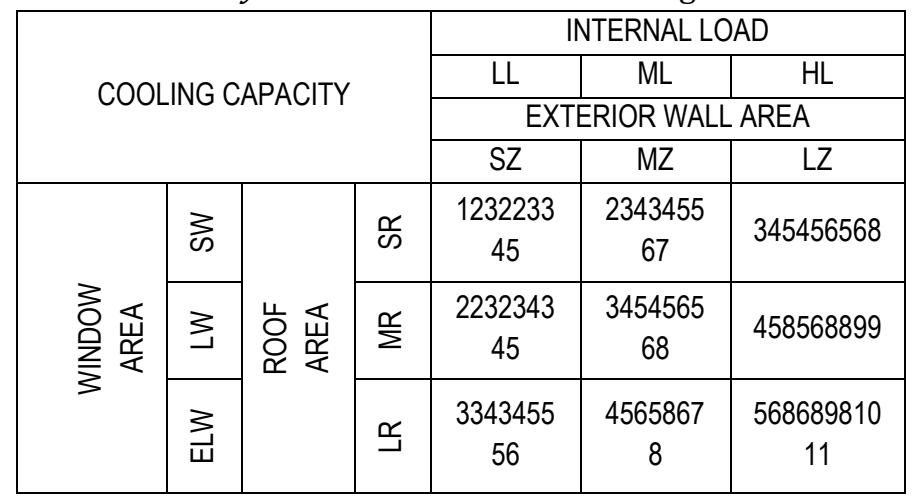

The following are the sample fuzzy rules for the model Rule 1. If (Window_ Area Is SW) And (Roof_ Area Is

SR) And (External_Wall_Area Is SZ) And (Internal_ Load Is LL) Then (Cooling_Capacity Is 1)

Rule 5. If (Window_Area Is SW) And (Roof_Area Is

MR) And (External_Wall_Area Is MZ)

And (Internal_Load Is LL) Then (Cooling Capacity Is 2)

Rule 20. If (Window_Area Is SW) And (Roof_Area Is

MR) And (External_Wall_Area Is SZ)

And (Internal_Load Is HL) Then (Cooling_Capacity Is 4)
Rule 30. If (Window_Area Is LW) And (Roof_Area Is LR) And (External_Wall_Area Is SZ)

And (Internal_Load Is LL) Then (Cooling_Capacity Is 3)

Rule 81. If (Window_Area Is ElW) And (Roof_Area Is

LR) And (External_Wall_Area Is LZ) And (Internal_Load Is ML) Then

(Cooling_Capacity Is 11)

\subsection{Model Validation:}

Randomly selected samples of the crisp values of input variables obtained during data collection are shown in Table 7. This shows the result of Cooling Load as output value generated from the human calculation procedures using Equations (1) - (7). The model also generated values of Cooling Load in BTUs for the tested 20 scenarios as shown in Table 7.

The result of human calculations and that of the model are displayed in the last two columns of Table 7. Similar trend using the two platforms for cooling capacity estimations is noted. The average value of the human calculation is 4319 , while that of the model is 4541. In 9 out of the 20 samples (45\%), the values of human calculated Cooling Load are higher than that of the model most of the difference are below 500BTUs. All others however have the values of model greater than that of the human calculation.

Table 7: Variables recorded from selected cases, human professional computation and the Model predictions.

\begin{tabular}{cccccccccc}
\hline S/N & $\begin{array}{c}\text { Window } \\
\text { Area }\left(\mathrm{m}^{2}\right)\end{array}$ & $\begin{array}{c}\text { Roof } \\
\text { Area } \\
\left(\mathrm{m}^{2}\right)\end{array}$ & $\begin{array}{c}\text { Exterior } \\
\text { Wall Area } \\
\left(\mathrm{m}^{2}\right)\end{array}$ & $\begin{array}{c}\text { People } \\
(\text { No. })\end{array}$ & $\begin{array}{c}\text { Appl. } \\
(\text { Watt })\end{array}$ & $\begin{array}{c}\text { Light } \\
(\text { Watt })\end{array}$ & $\begin{array}{c}\text { Total } \\
(\text { Watt) }\end{array}$ & $\begin{array}{c}\text { Human } \\
\text { Calculated } \\
(\text { BTUs })\end{array}$ & $\begin{array}{c}\text { Model } \\
\text { Predicted } \\
(B T U s)\end{array}$ \\
\hline 1 & 1.44 & 8.1 & 8.16 & 1 & 80 & 72 & 152 & 3100.1 & 2970 \\
2 & 1.44 & 9.6 & 7.56 & 2 & 180 & 72 & 252 & 3870.3 & 3630 \\
3 & 1.64 & 8.64 & 6.46 & 1 & 140 & 90 & 230 & 3359.1 & 3630 \\
4 & 1.64 & 9.72 & 9.16 & 3 & 240 & 72 & 312 & 4100.7 & 4800 \\
5 & 1.92 & 11.52 & 8.64 & 2 & 80 & 90 & 170 & 3011.3 & 3600 \\
6 & 2.16 & 12.96 & 9.99 & 2 & 60 & 36 & 96 & 2693.7 & 3700 \\
7 & 2.16 & 13.68 & 11.34 & 3 & 240 & 72 & 312 & 3866.2 & 5000 \\
8 & 2.16 & 15.2 & 23.34 & 4 & 250 & 108 & 358 & 5180.7 & 4800 \\
9 & 2.88 & 17.28 & 10.92 & 5 & 310 & 126 & 436 & 5261.9 & 5700 \\
10 & 4.36 & 28.8 & 13.64 & 3 & 180 & 90 & 270 & 4214.6 & 5000 \\
11 & 3.84 & 24.2 & 12.36 & 3 & 180 & 90 & 270 & 4151.5 & 4700 \\
12 & 3.36 & 16.5 & 9.24 & 2 & 100 & 18 & 118 & 3066.1 & 3700 \\
13 & 2.88 & 18.6 & 12.2 & 3 & 60 & 36 & 96 & 3811.7 & 3700 \\
14 & 4.36 & 26.04 & 12.44 & 3 & 180 & 54 & 234 & 4550.9 & 4500 \\
15 & 2.88 & 23.04 & 10.56 & 6 & 250 & 108 & 358 & 6178.7 & 5700 \\
16 & 2.88 & 24.96 & 10.46 & 2 & 170 & 108 & 278 & 6089.9 & 5400 \\
17 & 4.36 & 28.8 & 9.68 & 3 & 250 & 72 & 322 & 4851.5 & 5700 \\
18 & 3.84 & 27.9 & 4.16 & 5 & 370 & 72 & 442 & 6518.6 & 5700 \\
19 & 4.36 & 23.0 & 6.14 & 4 & 330 & 54 & 384 & 5812.1 & 5580 \\
20 & 1.44 & 6.5 & 4.8 & 1 & 170 & 72 & 242 & 2689.9 & 3300 \\
\hline
\end{tabular}




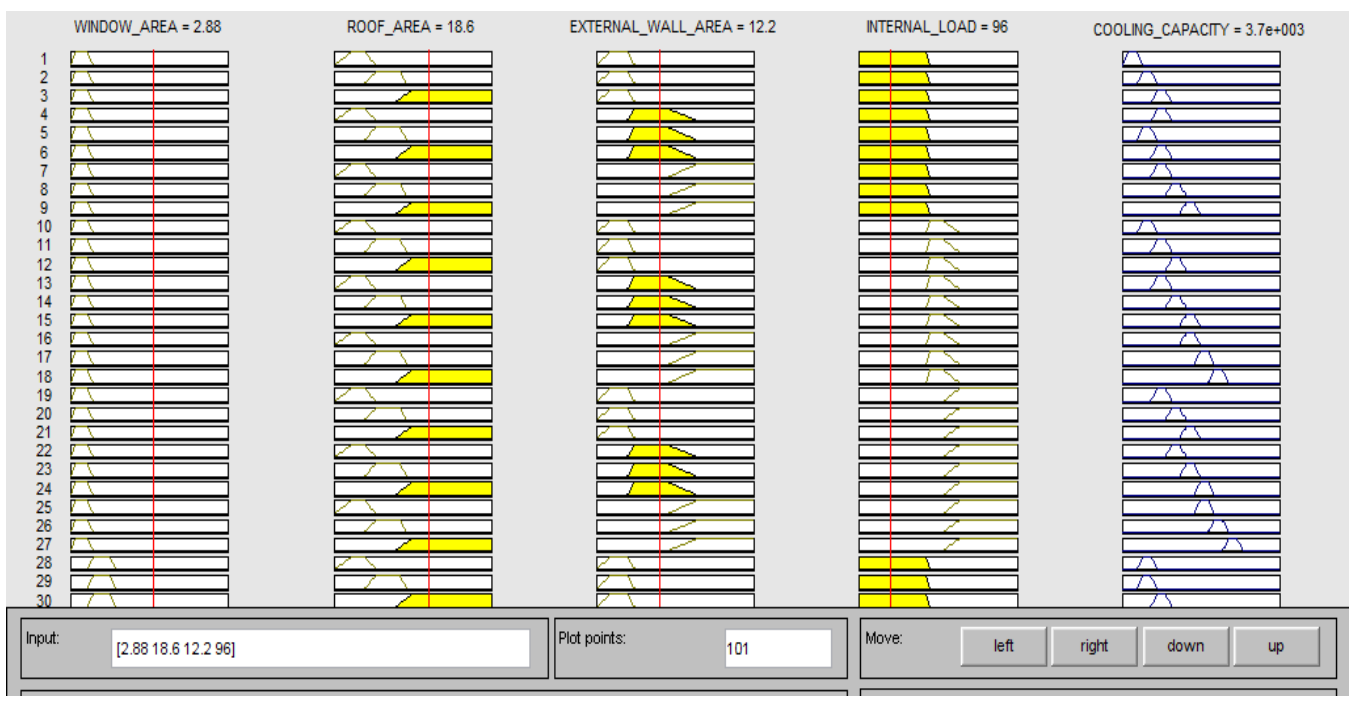

Figure 9: An interface of the model

Figure 9 shows the platform for rule evaluation and the display of results obtained as display in MATLAB environment. Since the model acts as totally interactive procedure, it also shows the users' interface for the model, where users communicate with the system. To use this platform, the user carefully key in all the four required input variables each to be separated by a single space in the order as displayed by the interface input columns. This includes values of window area $\left(\mathrm{m}^{2}\right)$, roof area $\left(\mathrm{m}^{2}\right)$, external wall area $\left(\mathrm{m}^{2}\right)$, and internal load (Watt) respectively. The output is displayed on the top of column five as the Cooling Load required for cooling of the room.

\subsection{Result of Statistical Analysis:}

The paired samples correlations output (Table 8) presents an hypothesis testing statistic which indicates how strongly related the two sets of variables are. The correlation value is close to 1 showing that the two sets of variables (model predictions and human calculations) are more related. The standard error mean of 130.72 obtained shows the standard error of the mean difference, indicating how close the sample mean is to the true mean of the overall population.

\section{Table 8: The output for the paired samples correlations test between the human calculated and the Model} predicted Cooling Load.

\begin{tabular}{|c|c|c|c|}
\hline Human Calculation \& & $\mathrm{N}$ & Correlation & Sig. \\
\cline { 2 - 4 } Model prediction & 20 & .880 & .000 \\
\hline
\end{tabular}

Table 9 presents the $\mathrm{t}$ obtained, degrees of freedom, and the two tailed level of significance. In this case, the t obtained is -1.695 , and, with 19 degrees of freedom, it is significant at least at the .001 alpha level. With this result, it can be concluded that the human calculations significantly do not differed from that of the model predictions. More specifically, by examining the difference between the two variables, we can conclude that on the average the model predictions are higher on average of 221.5 time more compared to that of human calculations.

Table 9: The output for the Paired-Sample T Test between the human calculated and the Model predicted Cooling Load.

\begin{tabular}{|l|l|l|c|c|c|}
\hline $\begin{array}{l}\text { Human } \\
\text { Calculation - } \\
\text { Model }\end{array}$ & \multicolumn{2}{|c|}{$\begin{array}{c}\text { 95\% Confidence } \\
\text { Interval }\end{array}$} & T & df & $\begin{array}{l}\text { Sig. (2- } \\
\text { tailed) }\end{array}$ \\
\cline { 2 - 4 } prediction & Lower & Upper & & & \\
\cline { 2 - 6 } & -495.1192 & 52.0692 & -1.695 & 19 & .106 \\
\hline
\end{tabular}

This model has shown to achieve the objectives for which it was developed. It mimics the human expert's verdict in the application area without major significant difference between human specialists, and the fuzzy logic model decisions. According to Hawking et al. [28] and Jones [29], when a model is successful at explaining events and meet the objective, we tend to attribute to it, and to the elements and concepts that constitute it, "the quality of reality or absolute truth". It is noted that most of the values of Cooling Load generated by human calculations comes in decimal. Rounding to the nearest whole number is necessary. For both platforms, available capacity of air conditioners next to the values recommended is selected. However for further efforts, inclusion of more variable(s) capable of capturing loads through doors, partitions to unconditioned spaces and 
infiltration can be considered for improvement of the model.

\section{CONCLUSION}

In this study, we have proposed a model for estimating the cooling requirement of specified residential rooms using fuzzy logic. The exemplar is capable of giving predictions comparable to that of human professionals. The developed fuzzy logic model is easy as it can be used and interpreted by all category of users. It is a valuable tool for constructors and home owners where human experts in the application area are uncommon.

\section{REFERENCES}

[1]. Idener, Modelling and simulation. Available from http://www.idener.es 2013. Retrieved October 23, 2014.

[2]. McLaughlin, J. A. and G. B. Jordan. "Logic models: a tool for telling your program's performance story". Evaluation and Planning. Vol. 22, 1999. pp. 65-72.

[3]. Millar, A., Simeone, R. S. and Carnevale J. T. "Logic models: a systems tool for performance management". Evaluation and program planning Vol.24, 2001. Pp. 73-81

[4]. Mohammad, R. E. "Systematic methodology of fuzzylogic modelling and control and application to robotics". 1997. Available from Available from https://tspace.library.utoronto.ca/bitstream. Retrieved December, 2013.

[5]. Mullen, C. E. and Bullard, C. W. 1994. "Room air conditioner system modeling". Air conditioning and refrigeration center. Project 41, Number 217 pp. 333 $-3115$

[6]. Cutler, D., Winkler, J., Kruis, N. and Christensen, C. "Improved modelling of residential air conditioners and heat pumps for energy calculations". 2013. Available from http://www.nrel.gov/docs/ fy13osti/56354.pdfRetrieved October, 2015

[7]. Lu, N., Xie, Y., Huang, Z.. "Air conditioner compressor performance model". 2008. Accessed from http://www.pnl.gov/main/publications. Retrieved September, 2015.

[8]. Mohammad, A. F. and Majid, B., "Comprehensive modelling of vehicle air conditioning loads using heat balance method". 2013. Available from http://www.sfu.caSAE International. Retrieved June, 2015.

[9]. Dan, L., Hanson, L. and Or, R. "The influence of virtual human model appearance on visual ergonomics posture evaluation", Applied Ergonomics, Vol. 38 Number 6, 2007, pp. 713-722.

[10]. Ramjeet, S. Y., Vijendra, P. S. Modelling academic performance evaluation using soft computing techniques; a fuzzy logic approach. International Journal on Computer Science and Engineering, Vol., 3 Number 2, 2011. pp.676-686.

[11]. Petr, D. D. "Computing in Economic and Finance - London. Risk Management and Fuzzy Logic". 2010. Available from http://www.petrdostal.eu/ papers/cla24.pdf. Retrieved June 6, 2011.

[12]. Hani, N. S. "Risk assessment of construction projects using network based adaptive fuzzy system". Available from www.slideshare.net/ theoniynell/ris... 2012. Retrieved November 12, 2012.

[13]. Kozlowska, E. Basic principles of fuzzy logic. 2012. Available at http://access.feld.cvut.cz . Accessed October 10, 2014.

[14]. Abdur, R., Khan, H., Ullah, A., Zia, U. R. "Application of Expert System with Fuzzy Logic in Teachers 'Performance Evaluation". International Journal of Advanced Computer Science and Applications, Vol.2, Number 2, 2011.

[15]. Mayilvaganan, M., Rajeswari, K., 2014 Health Care Analysis based on Fuzzy Logic Control System. International Journal of Computer Science Trends and Technology, Volume 2(4), pp. 119-12

[16]. Bansal, A., 2011. Trapezoidal Fuzzy Numbers (a,b,c,d): Arithmetic Behaviour. International Journal of Physical and Mathematical Sciences, Volume 2(1), pp 39-44

[17]. Adeyemi H. O., Adejuyigbe S. B., Ismaila S. O., Adekoya A. F. "Low back pain assessment application for construction workers". Journal of Engineering, Design and Technology, Vol. 13 Number 3, 2015, pp 419-434

[18]. Adeyemi, H. O., Adefemi, A. A., Akinyemi, O. O., Adefemi, 0. A. "A shoveling-related pain intensity prediction expert system for workers' manual movement of material" International Journal of Technology. Vol. 7 Number 4, 2016. pp. 603-615

[19]. ASHRAE HVAC. "Fundamentals handbook". 2001 Available from http://systemssolution.net/ cadtechno/0\%20sample/specs $\% 20 \& \% 20$ details/bo oks $\% 20$ mechanical/hvac/ashrae $\% 20$ hvac $\% 202001$ \%20fundamentals\%20handbook.pdf. Retrieved January 21, 2016.

[20]. Mustafa, K. G. and Kevin, M. P.“Avoiding Exponential Parameter Growth in Fuzzy Systems". IEEE Transactions on Fuzzy Systems, 2001, Vol. 9, Number 1, pp. 194-199.

[21]. Microsoft excel 2010

[22]. Ion Iancu, Fuzzy Logic - Controls, Concepts, Theories and Applications. University of Craiova (IIUC): In Tech, 2012.

[23]. Bilkent University (BU), "A Short Fuzzy Logic Tutorial". 2010. Accessed from http://cs.bilkent.edu.tr / zeynep/files/ Vol. 35, No. 3, July 2016 525 
short fuzzy logic tutorial.pdf. Retrieved October, 2014.

[24]. Lotfi, A., Andersen, H. C. Tsoi, A. C., "Matrix formulation of fuzzy rule based systems". IEEE Transactions on Systems, and Cybernetics-part B. Cybernetics, Vol. 26, 1996. 1083-4419

[25]. Waleed, K. A. "Advantages and Disadvantages of Using MATLAB for Solving Differential Equations in Engineering Application". International Journal of Engineering (IJE), Vol. 7 Number 1, 2013. pp. 25-31.

[26]. Kristian, S. "Introduction to MATLAB". Department of Applied Mathematics University of
Colorado. 2009. Available from http://amath.colorado.edu/computing/MATLAB/Tu torial/Intro.html. Retrieved 10-07-2011.

[27]. Kent State University (KSU). "SPSS Paired Sample Test". 2016. Available from http://libguides.library. kent.edu/SPSS. Accessed February 9, 2016.

[28]. Hawking, S. W., and Leonard, M. "What is Reality?" The grand design. New York: Bantam, 2010, pp. 37-59. Print

[29]. Jones, A. Z. "What is model-dependent realism?" 2011. Available from www.physics.about.com. Accessed February 20, 2014. 